\title{
Doğal Atık Malzemeler ve Biyoçarları ile Biyobozunur Özellikte Yeni Epoksi-bazlı Kompozitlerin Hazırlanması ve Karakterizasyonu
}

\author{
Süheyla KOCAMAN ${ }^{* 1}$, Gülnare AHMETLí ${ }^{1}$, Merve SOĞANCIOĞLU \\ ${ }^{1}$ Selçuk Üniversitesi, Mühendislik Fakültesi, Kimya Mühendisliği Bölümü, Konya \\ ${ }^{2}$ Selçuk Üniversitesi, Mühendislik Fakültesi, Çevre Mühendisliği Bölümü, Konya
}

Geliş tarihi: 13.02.2018 Kabul tarihi: 29.06.2018

Öz

Bu çalışmada doğal atık malzemelerden ceviz kabuğu (CK) ve pirina bisfenol-A tipi epoksi reçine (ER) kompozitlerinin hazırlanması için dolgu maddesi olarak kullanılmıştır. Ayrıca, doğal takviye malzemeleri $700{ }^{\circ} \mathrm{C}$ 'da piroliz edilerek katı ürün atığ 1 çarla da kompozitleri oluşturulmuştur. Epoksi reçinede dolgu oranı \%10-50 aralığında değiştirilerek kompozitlerin mekanik, elektriksel, iletkenlik ve termal özelliklerine dolgu maddesi oranının etkisi araştırılmıştır. Çarların morfolojisi taramalı elektron mikroskobu (SEM) ile incelenmiştir. Ayrıca, elde edilen biyobazlı kompozit malzemeler özel olarak hazırladığımız toprağa gömülerek bozunma süreleri (biyobozunurluk testi) belirlenmiştir.

Anahtar Kelimeler: Epoksi reçine, Biyoçar, Biyokompozit

\section{Preparation and Characterization of New Epoxy-Based Composites with Biodegradable Natural Waste Materials and Biochars}

\begin{abstract}
In this study, natural waste materials (walnut shell waste and pirina waste) were used as a filler material to prepare bisphenol-A type epoxy (ER) composite materials. In addition, natural reinforcement materials were pyrolyzed to form solid product such as char and its composites were prepared. The filler ratio in epoxy resin has been changed in the range of $10-50 \%$. The effect of filler ratio on the mechanical, electrical conductivity and thermal properties of composites has been investigated. The morphology of the chars was characterized by scanning electron microscopy (SEM). In addition, prepared biodegradable composite materials were buried in specially prepared soil to determine their disposal time (biodegradability test).
\end{abstract}

Keywords: Epoxy resin, Biochar, Biocomposite

"Sorumlu yazar (Corresponding author): Süheyla KOCAMAN, suheyla@selcuk.edu.tr 
Doğal Atık Malzemeler ve Biyoçarları ile Biyobozunur Özellikte Yeni Epoksi-Bazlı Kompozitlerin Hazırlanması ve Karakterizasyonu

\section{GİRIŞ}

Epoksi reçine, gelişmiş kompozitlerde genellikle tercih edilen ve her tür takviye veya dolgu ile kullanılabilen bir reçinedir. Günümüzde epoksi reçinelerin havacılik ve uzay sanayi, otomotiv sanayi, yapıştırıcılar, tutkallar, boyalar, yüzey kaplama gibi geniş uygulama alanları bulunmaktadır [1]. Epoksi reçinelerin mekanik özelliklerini birçok faktör etkilemektedir: $\mathrm{Tg}$ dışında, çapraz bağ yoğunluğu, mikroyapı, takviye ile matris arasındaki ara yüzey performansı, reçine kısımlarının esnekliği vb. Kürleştirici maddelerin kimyasal yapısına ve işlem koşullarına bağlı olarak kürleşmiş epoksi reçinelerinin özellikleri değişir. Epoksi kompozit sistemlerinde, epoksi sistemlerine farklı özellikler ve morfoloji kazandıran amin ve anhidrit esaslı kür ajanları kullanılabilir [2]. Genel olarak, yüksek sicaklıkta kürleşen reçine sistemleri, oda sicaklığında işlem görmüş olanlara kıyasla, daha yüksek camsı geçiş sıcaklığ1, mukavemet ve sertlik gibi gelişmiş özelliklere sahip olurlar $[3,4]$.

Son y1llarda polimer ürünler üretimindeki artış özellikle çevre konusunda artan bir endişeyi de beraberinde getirmiştir. Bu durumda yeni biyobazlı ve/veya biyobozunur malzemelerin geliştirilmesi bu konuda öncülük etmektedir. Biyobazlı kompozitlerin en büyük avantajının onların biyobozunabilirliği, dolayısıyla çevreye atık materyal olarak güvenle birakılabilmesi ve otomotiv sektörü, ev içi mobilyaları, elektronik, kaplama materyali, biyomedikal, ambalajlamada plastik kompozitlerin yerini alarak uygulanabilecek olmasidır [5].

Bir polimer matrisine dolgu maddelerinin dahil edilmesi arzu edilen bir dizi özellikleri elde etmek için hızlı ve düşük maliyetli bir yöntemdir. Özellikle aktif dolgu maddeleri, termal ve elektriksel iletkenlik, sürtünme, aşınma direnci ve alev direnci gibi özellikleri değiştirmek veya geliştirmek için yaygın olarak kullanılmaktadırlar [6]. Öte yandan, piyasaların rekabeti ürünlerin en iyi maliyet ve performans dengesini de beraberinde getirmiş, bundan dolayı ucuz ve doğal dolgu maddelerinin kullanılması özellikle ilgi çekici bir hal almıştır [7,8]. Böylece, biyolojik olarak parçalanabilen polimer kompozitlerin önemi daha da artmış ve plastik malzeme kullanımından sonra oluşacak katı atık sorununa bu şekilde çözüm önerilmiştir [9].

Çar, oldukça kararlı bir formda olup karbondan daha zengin gözenekli bir materyaldir [10]. Karbon, fulleren, grafen, karbon karası gibi yarı kristal faz ve çeşitli amorf fazlar gibi birçok form sergiler. $\mathrm{sp}^{2}$ karbon yapılarının varlığ malzemelerinin elektriksel iletkenliği kapsayan daha geniş uygulamalar için kullanılma olasılığını arttırır [11,12]. İletken polimer kompozitlerin metalik iletkenlere göre birçok avantajı vardır. Düşük maliyetle kolayca şekillendirilebilirler, hafiftirler, korozyon direnci sağlarlar ve geniş bir elektrik iletkenliği sunar. Özaytekin ve Kar [13] oligoazometin/PET çarı kompozitlerinin elektriksel iletkenliklerini araştırmışlardır ve çarın yapısındaki tereftalik asit nedeniyle iyot katkılı oligoazometin/PET çarı kompozitlerinin elektriksel iletkenliklerinin $10^{-5}-10^{-4} \mathrm{Scm}^{-1}$ den $10^{-2} \mathrm{Scm}^{-1}$ 'e yükseldiğini belirtmişlerdir. Birkaç araştırmacı epoksi kompozitlerin elektriksel iletkenliklerinde nanokarbon takviyesi ile iyileşme olduğunu bildirmiştir $[14,15]$.

Kompozit malzeme kullanımının giderek arttığı günümüzde, bu çalışmada yenilenebilir kaynaklardan olan atı dolgu malzemeleri kullanarak biyobazlı kompozitlerin hazırlanması ve karakterizasyonunun yapılması hedeflenmiştir. Hem kompozit maliyetinin düşürülmesi, hem de biyobozunurluk, mekanik ve termal özelliklerinin iyileştirilmesine olan etkisini incelemek için çeşitli doğal dolgu malzemeleri ve bunların pirolizinden elde edilen katı ürün çarları farklı oranlarda epoksi matris faza ilave edilmiştir. Bu araştırma biyobazlı kompozitlerin bu türleri için yapılan ilk çalışmadır. Katı faz olan çar (kok), orijinine bağlı olarak çoğunlukla adsorban olarak değerlendirilmektedir. Endüstriyel kullanım alanına sahip ürün olarak değerlendirilmesi üzerine fazla uygulama bulunmamaktadır. Epoksi reçinede PET çarının kullanımı ile ilgili ilk çalışma da tarafımızdan yapılmıştır [16]. Çalışmada kullanılan hem pirinanın, hem de ceviz kabuğunun $700{ }^{\circ} \mathrm{C}$ 'da pirolizinden elde edilen çarların, kompozit yapımında dolgu olarak değerlendirilmesi hem 
ekonomik olarak, hem de çevre açısından yararlı olacağı düşünülmektedir. Çalışma sonuçları uygulamaya aktarıldığı takdirde ülke ekonomisine hem mali hem de saygınlık açısından yarar sağlayacağı düşünülmektedir.

\section{MATERYAL VE METOT}

\subsection{Materyal}

Çalışmada matris sistemi olarak bisfenol-A tipi ticari epoksi reçine (ER) (NPEK 114, Konuray Kimya ve Sanayi Ltd. Şti.) kullanılmıştır. NPEK 114 epoksi reçinesinin özellikleri Çizelge 1'de verilmiştir.

Çizelge 1. NPEK 114 epoksi reçinesinin özellikleri

\begin{tabular}{|l|l|}
\hline Özellikler & Değer \\
\hline Epoksi eşdeğer ağırlık (g/eq) & $190-210$ \\
\hline Viskozite (cps, at $\left.25^{\circ} \mathrm{C}\right)$ & $600-1200$ \\
\hline Renk (Gardner) & 1,0 mak. \\
\hline
\end{tabular}

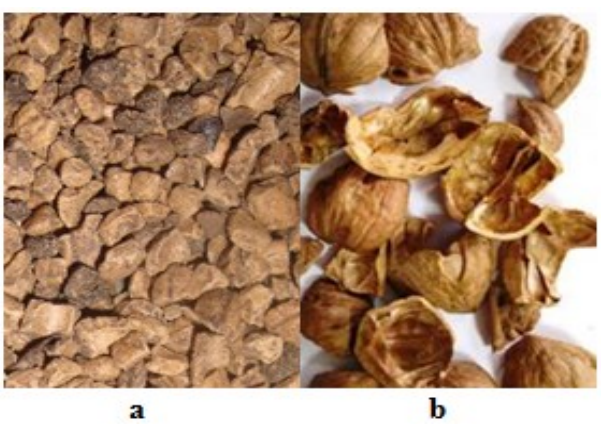

Şekil 2. Atık: a) pirina, b) CK

\subsection{Pirolizle Çar Eldesi}

Piroliz sistemi; güç kontrol, 1sıtma, soğutmayakalama ve gaz depolama olmak üzere dört kisımdan

ve sürükleyici gaz olarak kullanılmak üzere azot gazı tüpünden oluşmaktadır (Şekil 3).

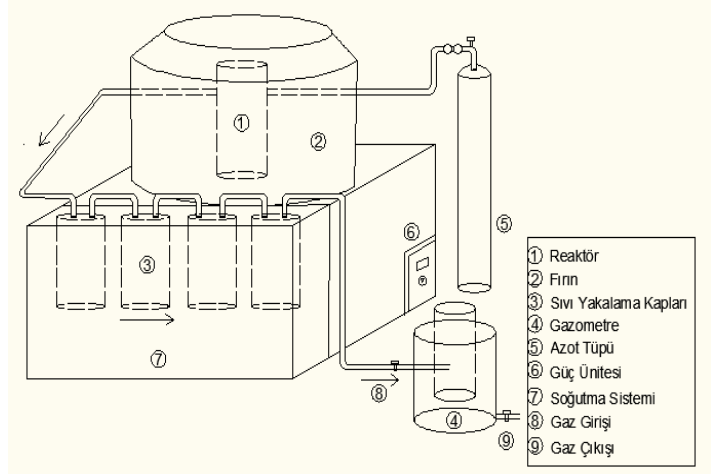

Şekil 3. Laboratuvar ölçekli piroliz sistemi akım şemas1

Reaktör $11 \mathrm{~cm}$ çapında ve $24 \mathrm{~cm}$ uzunluğundadır ve paslanmaz kromdan yapılmıştır. Reaktörde 0$900^{\circ} \mathrm{C}$ sicaklıkta çalıșmak mümkündür. Reaktörü istenilen sıcaklığa getirmek ve bu sicaklıkta sabit tutmak için, reaktör yüksek sıcaklık seramik firın içerisine dikey olarak yerleştirilmiştir. Fırın $14 \mathrm{~cm}$ iç çapında $30 \mathrm{~cm}$ uzunluğundadır. Fırın iç k1sminda $1,5 \mathrm{~kW}$ gücüne sahip A-1 kantal tel sarılmıştır. Fırın PID kontrol edici ile kontrol edilmektedir. Reaktörün iç sıcaklığı ise, fırın dış kısmından uzatılan $\mathrm{NiCr}-\mathrm{Ni}$ isıl çift ile reaktörün merkezinde sicaklık ölçümü ve kontrolü yapilabilmektedir [17]. 
Doğal Atık Malzemeler ve Biyoçarları ile Biyobozunur Özellikte Yeni Epoksi-Bazlı Kompozitlerin Hazırlanması ve Karakterizasyonu

\subsection{Kompozitlerin Hazırlanması}

Biyobazlı dolgu materyalleri (pirina, $\mathrm{CK}$ ve çarları) önce öğütülmüş, ardından da 230 mesh elekten elenerek $(\leq 63 \mu \mathrm{m})$ kompozitlerin hazırlanmasında kullanılmıştır. Farklı oranlarda (kütlece \%10-50) epoksi reçineye eklenen dolgular mekanik karıştırıcıda (2000 rpm) 1 saat ve ardından dolgu maddelerinin daha iyi dağılımının gerçekleşmesi için 1 saat boyunca $60{ }^{\circ} \mathrm{C}$ 'da ultrasonik banyoda bekletilmiştir. Daha sonra kütlece \%30 epoksi kürleştirici ve \%1 epoksi hızlandırıcı ilave edilerek kalıp içine aktarılmış, 1 saat hava kabarcıkları giderilene kadar oda sıcaklığında bekletilmiştir. Kompozitler, ASTM D 638 standartlarına göre paslanmaz-çelik kalıp içinde hazırlanmıştır (Şekil 4).

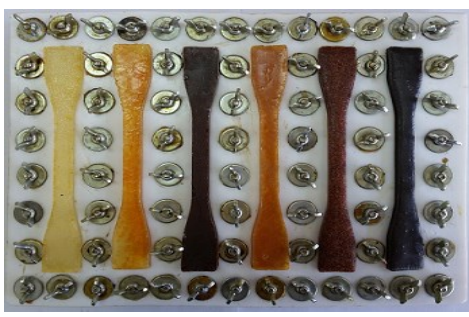

Şekil 4. ASTM D 638 standartlarındaki kalıpta hazırlanmış kompozitler

\subsection{Analiz ve Testler}

Epoksi matris fazı ile biyobazlı dolgu malzemeleri arasındaki arayüzün aydınlatılması için Philips XL30 SFEG marka SEM cihazı kullanılmıştır. Hazırlanan biyobazlı kompozitlerin mekanik özelliklerinden sertlikleri A Shore Durometer TH 210 ile, çekme uzaması, çekme dayanımları ve Young modülü değerleri ise TST-Mares/TS-mxe marka çekme testi cihazı ile belirlenmiştir. Elektriksel iletkenlik analizi için kesit kalınlığı bilinen kompozit numunesi, önce metanol daha sonra da hekzan ile temizlenerek, 1-10 V aralığında 4 nokta prob tekniğiyle çalışan FPP-470 marka elektrometre ile gerçekleştirilmiştir. Kompozitlerin termal dayanımlarının belirlenmesi için Seteram Thermagravimetric Analyzer cihazında termal analizleri yapılmıştır. FTIR spektrumları, doğal kabukların ve çarlarının kimyasal yapılarını tayin etmek için Bruker-
Platinum cihazı kullanılarak 70, 500 ve $4000 \mathrm{~cm}^{-1}$ arasındaki dalga boyunda, ATR aksesuarı kullanılarak $4 \mathrm{~cm}^{-1}$ çözünürlükte kaydedilmiştir. $\leq 63 \mu \mathrm{m}$ boyutundaki dolgu maddesinin partikül karakterizasyonu için CILAS 1190 lazer partikül büyüklüğü analiz cihazı kullanılmıştır.

\subsection{Biyobozunurluk Testi}

Kompozitlerin biyobozunurluk süreçleri için; literatürde verilen bilgilere göre simüle toprak karışımı hazırlanmıştır. Simüle toprak içeriği; \%23 kum, \%23 tını, \%23 yarı taze-yarı yanmış inek gübresi (literatürde inek gübresi olarak verilen kısım, bu çalışmada doğa koşullarına daha uygun olması açısından yarı yanmış-yarı taze gübre olarak kullanılmıştır) ve \%31 distile sudan oluşmaktadır [9]. Hazırlanan simüle toprak Şekil 5'de verilen plastik kap içerisine konulmuştur. Daha sonra hazırlanan her bir kompozit numunesi plastik kap içerisindeki bölmelere yerleştirilerek 1 y1l boyunca numunelerin rutubet ve biyobozunma özellikleri üzerindeki değişimler için bekletilmiştir.

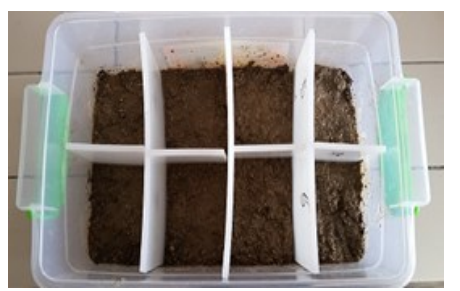

Şekil 5. Kompozit örneklerinin konulduğu özel toprak karışımı içeren plastik kap

\section{ARAŞTIRMA SONUÇLARI VE TARTIŞMA}

\subsection{Dolgu Maddelerinin Karakterizasyonu}

\subsubsection{FTIR Analizi}

Şekil 6'da pirina ve pirina çarının, Şekil 7'de CK ve CK çarının FTIR spektrumları verilmiştir. Şaf pirinanın FTIR spektrumunda $3349 \mathrm{~cm}^{-1}$, de O-H gerilmesi; $1595 \mathrm{~cm}^{-1}$ ve $1515 \mathrm{~cm}^{-1}$, de aromatik $\mathrm{C}=\mathrm{C}$ gerilmesi; $1731 \mathrm{~cm}^{-1}$, de polisakkaritlerde ve ksilenlerde bulunan konjuge olmayan $\mathrm{C}=\mathrm{O}$ grubu gerilmesi; $2925 \mathrm{~cm}^{-1}, 1460 \mathrm{~cm}^{-1}$ ve $1370 \mathrm{~cm}^{-1}$, de 
$-\mathrm{CH}_{2}-$ ve $-\mathrm{CH}_{3}$ gruplarının $\mathrm{C}-\mathrm{H}$ gerilmesi; $1421 \mathrm{~cm}^{-1}$ dalga boyunda ise $\mathrm{C}-\mathrm{H}$ aromatik halka titreşimi olduğu görülmektedir. $1325 \mathrm{~cm}^{-1}$ deki bant, siringil birimlerinin (C-O) varlığına ve $1031 \mathrm{~cm}^{-1}$ ve $1265 \mathrm{~cm}^{-1}$ deki piklerin, ligninin siringil (syringyl) ve guasil (guaicyl) (C-O) halkalarına ait olmasına bağlanabilir.
Ayrıca çarlar için $1670 \mathrm{~cm}^{-1}$ civarında görülen bant, ester bağından kaynaklanmaktadır. $1076 \mathrm{~cm}^{-1}$ ve $1176 \mathrm{~cm}^{-1}$, de pirinanın selüloz, hemiselüloz ve ligninindeki karakteristik $\mathrm{C}-\mathrm{O}-\mathrm{C}$ grubuna ait küçük C-O gerilme bantları olabilir. Pirinadaki fenolik $\mathrm{O}-\mathrm{H}$ yaklaşık $1252 \mathrm{~cm}^{-1}$, de görülmüştür.

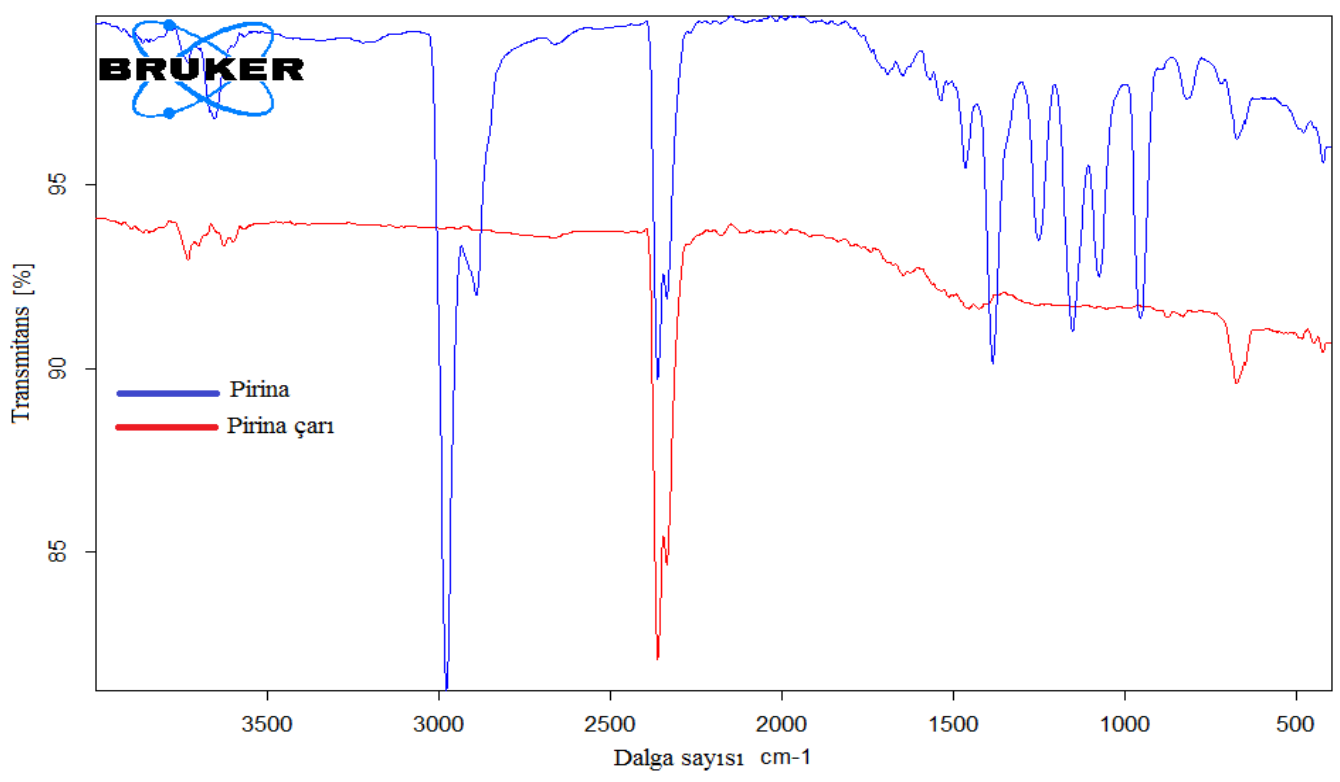

Şekil 6. Pirina ve pirina çarının FTIR spektrumları

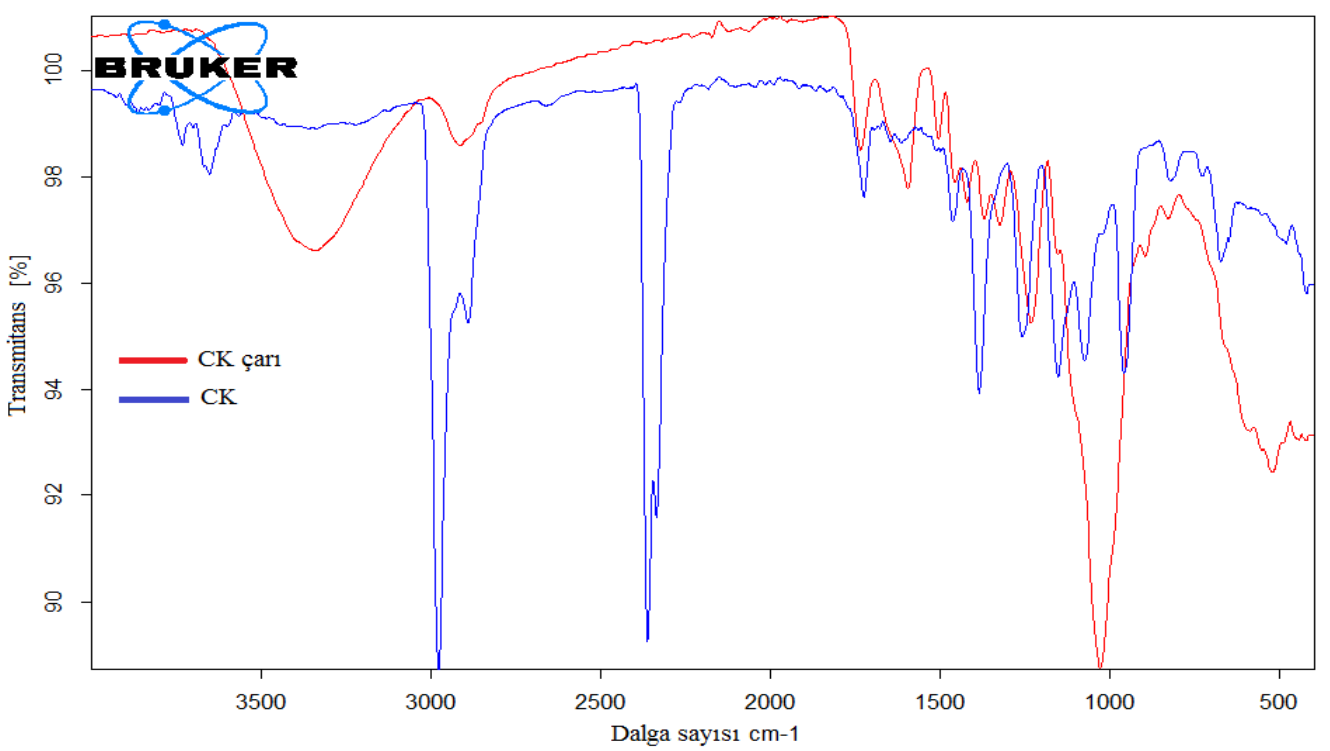

Şekil 7. CK ve CK çarının FTIR spektrumları 
Doğal Atık Malzemeler ve Biyoçarları ile Biyobozunur Özellikte Yeni Epoksi-Bazlı Kompozitlerin Hazırlanması ve Karakterizasyonu

\subsubsection{SEM/EDX ve Partikül Boyutu Analizi}

$700{ }^{\circ} \mathrm{C}$ 'da pirolizle elde edilen pirina ve $\mathrm{CK}$ çarlarının SEM/EDX görüntüleri Şekil 8'de; EDX analiz sonuçları ise Çizelge 3 'de verilmiştir.
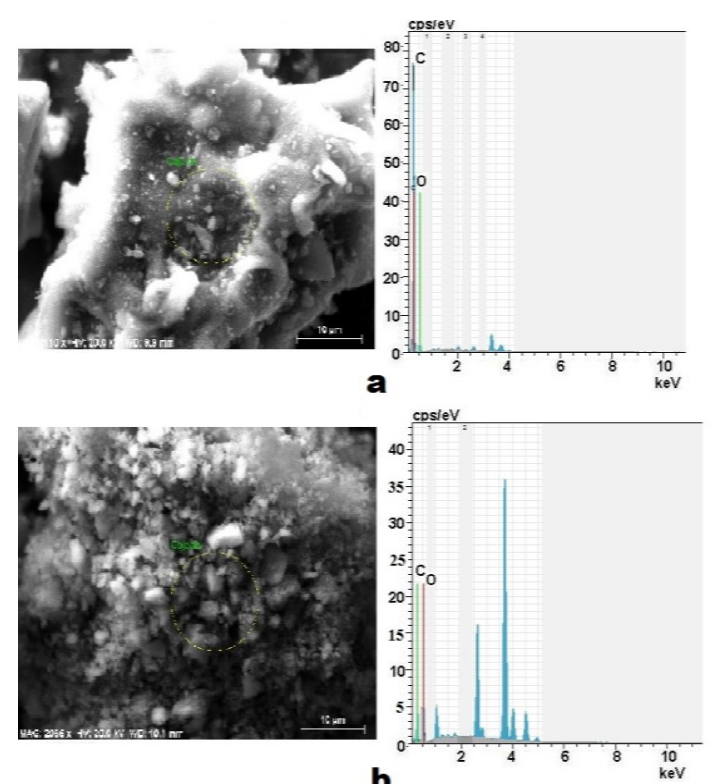

Şekil 8. Çarların SEM/EDX görüntüleri: a) pirina çarı; b) CK çarı

SEM görüntülerinden, piroliz sırasında oluşmus pirina çarı parçacıkların daha az gözenekli ve aglomera olduğu, CK çarı yüzeyinin ise küçük parçacık dağılımlı olduğu görülmektedir. Çarların farklı morfolojik yapılarının, pirina ve CK'nın farklı yoğunluklara sahip olmalarından kaynaklandığı düşünülmektedir [18]. Elementel analiz sonuçları, çarların karbon ve oksijen içeriklerinin sırasıyla \%71,61-76,21 ve $\% 23,79-28,38$ aralığında değiştiğini göstermiștir. Her iki çar için $\mathrm{O} / \mathrm{C}$ oranının düşük olması $(0,33-0,40)$ çarların kimyasal yapılarındaki polar grupların az olmasını ve daha düşük hidrofilikliğe sahip olduklarını göstermektedir [19].

Çizelge 3. EDX analiz sonuçları

\begin{tabular}{|c|c|c|}
\hline \multirow{2}{*}{ Çar } & \multicolumn{2}{|c|}{ Element (kütlece \%) } \\
\cline { 2 - 3 } & C & O \\
\hline Pirina çar1 & 71,61 & 28,38 \\
\hline CK çar1 & 75,22 & 24,77 \\
\hline
\end{tabular}

Şekil 9, CK çarının parçacık boyutu dağılımını göstermektedir. $\mathrm{Bu}$ analiz verilerine göre, partiküllerin çapları $\% 10, \% 50$ ve $\% 90$ 'da sirasılyla $5,69 \mu \mathrm{m}, 26,37 \mu \mathrm{m}$ ve $58,07 \mu \mathrm{m}$ 'dir.

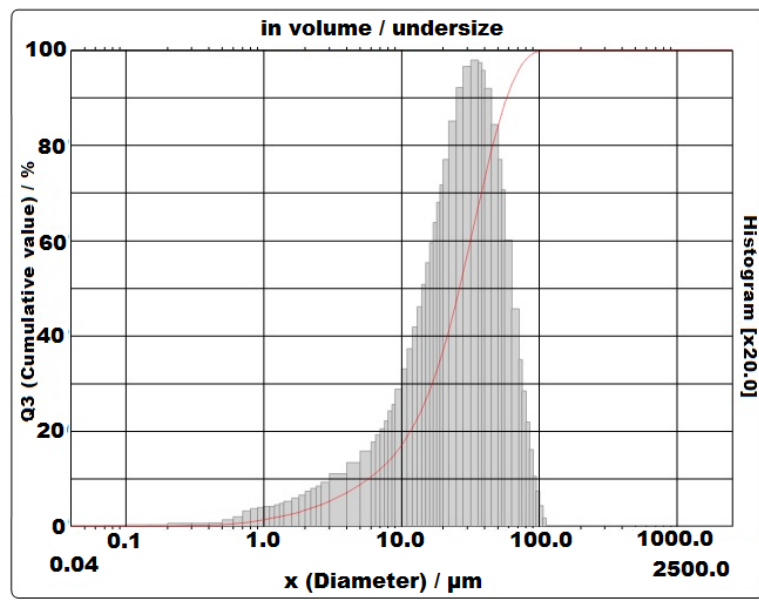

Şekil 9. CK çarının boyut analiz grafiği

\subsubsection{TGA}

Pirina, ceviz kabuğu ve çarlarının termal dayanımlarının belirlenmesi için termogravimetrik analiz (TGA) yapılmış, sonuçlar Şekil 10 ve Çizelge 4'de verilmiştir.

Çizelge 4. Pirina, CK ve çarlarının termal özellikleri

\begin{tabular}{|c|c|c|c|c|c|c|}
\hline & $\begin{array}{l}\text { BBS } \\
\left({ }^{\circ} \mathrm{C}\right)\end{array}$ & $\begin{array}{c}\mathbf{T}_{5} \\
\left({ }^{\circ} \mathbf{C}\right)\end{array}$ & $\begin{array}{l}\mathrm{T}_{10} \\
\left({ }^{\circ} \mathrm{C}\right)\end{array}$ & $\begin{array}{c}\mathbf{T}_{\mathbf{5 0}} \\
\left({ }^{\circ} \mathbf{C}\right)\end{array}$ & $\begin{array}{c}\mathbf{6 0 0} \\
{ }^{\circ} C^{\prime} d a \\
\text { kalıntı } \\
(\%)\end{array}$ & $\begin{array}{c}\mathbf{8 5 0} \\
{ }^{\circ} C^{\prime} \text { da } \\
\text { kalıntı } \\
(\%)\end{array}$ \\
\hline \begin{tabular}{|l|} 
Pirina \\
\end{tabular} & 53 & 219 & 377 & 482 & 5,3 & 2,2 \\
\hline \begin{tabular}{|c} 
Pirina \\
çarı
\end{tabular} & 180 & 162 & 650 & - & 90,5 & 84,7 \\
\hline CK & 45 & 82 & 222 & 339 & 27,1 & 23,1 \\
\hline $\begin{array}{l}\text { CK } \\
\text { çarı }\end{array}$ & 46 & 636 & - & - & 95,7 & 91,9 \\
\hline
\end{tabular}

[BBS: Birinci bozunma sıcaklığı: $\mathrm{T}_{5}, 10,50: \% 5$, $\% 10$ ve $\% 50$ bozunmanın gerçekleştiği sıcaklıklar]

TGA sonuçlarından, pirina ve CK çarlarının termal dayanımının saf pirina ve CK'ya göre çok yüksek olduğu görülmektedir. $\mathrm{T}_{5}, \mathrm{~T}_{10}$ ve $\mathrm{T}_{50}$ sıcaklıkları (sırasıyla \%5, \%10 ve \%50 kütle kaybının olduğu sıcaklıklar), kompozitlerin termal kararlılığını 
gösteren ana göstericilerdirler. Çizelge 4'den çarların $\mathrm{T}_{5}, \mathrm{~T}_{10}$ ve $\mathrm{T}_{50}$ sıcaklıklarının, saf $\mathrm{CK}$ ve pirinaya göre daha yüksek olduğu görülmektedir. Çarlar kendi arasında kıyaslanacak olursa, $850{ }^{\circ} \mathrm{C}$ 'da CK çarının kalıntı oranı \%91,9 iken pirina çarının kalıntı oranı \%84,7'dir. Dolayısıyla CK çarının termal dayanımının pirina çarından daha yüksek olduğu söylenebilir.

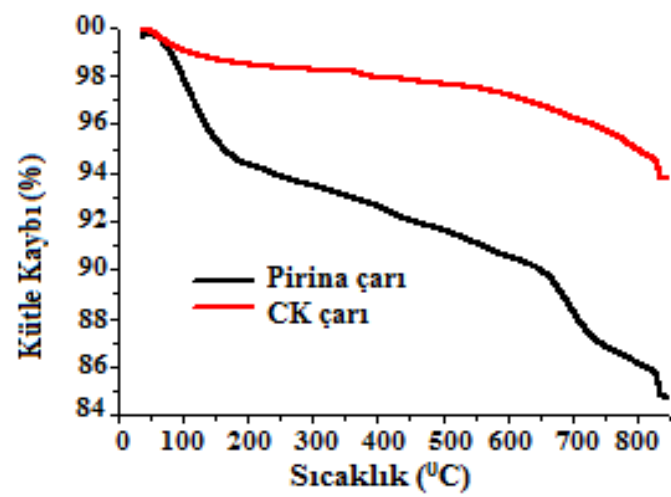

a

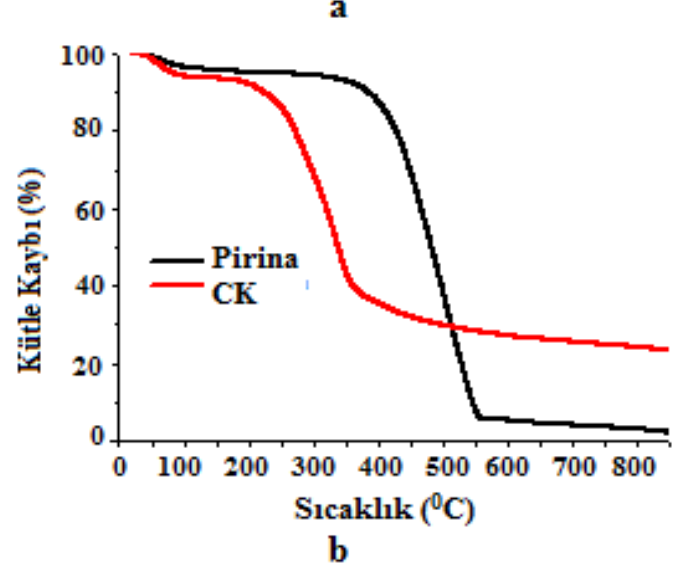

Şekil 10. a) Pirina ve CK çarlarının; b) Pirina ve CK'nın TGA eğrileri

\subsection{Kompozitlerin Karakterizasyonu}

\subsubsection{Kompozitlerin Mekanik Özellikleri}

Bisfenol-A tipi epoksi reçine bazlı pirina ve pirina çarı kompozitlerinin çekme testi sonuçları Çizelge 5'de verilmiştir. Saf ER için yapılan çekme testinden, \%0,805'lik çekme uzaması ve $49 \mathrm{MPa}$ 'lk bir çekme dayanımı değerleri elde edilmiştir. Saf ER'nin çekme uzaması tüm pirina ve çar içeriklerinde azalmıștır. Kompozitlerin en uygun çekme mukavemeti değerleri için katı dolgu oranı pirina ve pirina çarı için sırasıyla, ağırlıça $\% 30$ ve \%20 olarak belirlenmiştir; bu dolgu dozlarındaki çekme mukavemeti değerleri ise yine sirasiyla $69 \mathrm{MPa}$ ve $137 \mathrm{MPa}$ olarak tespit edilmiştir. Her iki tür kompozitlerin elastisite modül değerlerinin yakın olmasına karşın, çekme uzaması değerleri saf pirina kompozitlerinde daha yüksek tespit edilmiştir.

Çizelge 5. Saf epoksi reçine ve pirina/pirina çarı kompozitlerinin çekme testi sonuçları

\begin{tabular}{|c|c|c|c|}
\hline $\begin{array}{c}\text { Dolgu } \\
\text { (kütlece } \\
\text { \%) }\end{array}$ & $\begin{array}{c}\text { Çekme } \\
\text { uzaması } \\
\text { (\%) }\end{array}$ & $\begin{array}{c}\text { Çekme } \\
\text { dayanımı } \\
\text { (MPa) }\end{array}$ & $\begin{array}{c}\text { E- } \\
\text { modül } \\
\text { (GPa) }\end{array}$ \\
\hline \multicolumn{4}{|c|}{ ERE 114 epoksi reçinesi (ER) } \\
\hline- & 0,805 & 49 & 3,5 \\
\hline 10 & 0,765 & 55 & 5,6 \\
\hline 20 & 0,630 & 61 & 6,2 \\
\hline 30 & 0,530 & 69 & 6,7 \\
\hline 40 & 0,494 & 51 & 6,3 \\
\hline 50 & 0,402 & 50 & 6,1 \\
\hline \multicolumn{5}{|c|}{ ER/pirina çarı kompozitleri } \\
\hline 10 & 0,432 & 119 & 6,7 \\
\hline 20 & 0,475 & 137 & 6,9 \\
\hline 30 & 0,460 & 129 & 7,2 \\
\hline 40 & 0,355 & 91 & 6,1 \\
\hline 50 & 0,301 & 87 & 6,1 \\
\hline
\end{tabular}

Çizelge 6'da CK ve CK çarı kompozitlerinin çekme testi sonuçları verilmiştir. Çizelge 6'dan görüldüğü gibi, kompozitlerin en uygun çekme dayanımı değerleri için katı dolgu miktarı CK ve CK çarı için sırasıyla, ağırlıça $\% 30$ ve $\% 30$ olarak belirlenmiştir; bu dolgu dozlarındaki çekme dayanımı değerleri ise yine sırasıyla $93 \mathrm{MPa}$ ve $113 \mathrm{MPa}$ olarak tespit edilmiştir. Her iki tür kompozitlerin hem çekme uzaması, hem de elastisite modül değerleri yakın bulunmuştur. Tüm kompozitler için bir karşılaştırma yapılırsa, genelde saf atıklarla yapılan kompozitlerde CK atığı kompozitleri; çarlarla yapılan kompozitlerde ise pirina çarı kompozitleri daha yüksek çekme dayanımı değerlerine sahip olmuşlardır. 
Doğal Atık Malzemeler ve Biyoçarları ile Biyobozunur Özellikte Yeni Epoksi-Bazlı Kompozitlerin Hazırlanması ve Karakterizasyonu

Çizelge 6. CK ve CK çarı kompozitlerinin çekme testi sonuçları

\begin{tabular}{|c|c|c|c|}
\hline $\begin{array}{c}\text { Dolgu } \\
\text { (kütlece \%) }\end{array}$ & $\begin{array}{c}\text { Çekme } \\
\text { uzaması (\%) }\end{array}$ & $\begin{array}{c}\text { Çekme } \\
\text { dayanımı (MPa) }\end{array}$ & $\begin{array}{c}\text { E-modül } \\
\text { (GPa) }\end{array}$ \\
\hline \multicolumn{4}{|c|}{ ER/CK kompozitleri } \\
\hline 10 & 0,698 & 67 & 7,5 \\
\hline 20 & 0,706 & 74 & 6,2 \\
\hline $\mathbf{3 0}$ & 0,725 & 93 & 8,1 \\
\hline 40 & 0,545 & 85 & 8,4 \\
\hline 50 & 0,509 & 86 & 7,9 \\
\hline \multicolumn{4}{|c|}{ ER/CK çarı kompozitleri } \\
\hline 10 & 0,711 & 85 & 7,1 \\
\hline 20 & 0,734 & 102 & 7,4 \\
\hline 30 & 0,734 & 113 & 7,3 \\
\hline 40 & 0,568 & 83 & 7,3 \\
\hline 50 & 0,541 & 75 & 7,1 \\
\hline
\end{tabular}

Kompozitlerin sertlik ölçüm değerleri ise Şekil 10'da verilmiştir. Şekil 11'de görüldüğü gibi, takviye oranı \%30-40 oranına kadar arttıkça kompozitlerin sertlik değerleri artmış, \%50 oranında ise çok az bir azalma görülmüştür. Tüm kompozitlerin sertlik değerleri 80 Shore D'nin üzerinde olmuştur. Pirina bazlı kompozitlerde çar takviyesi daha etkili iken, diğer tür kompozitlerde hem CK, hem de CK çarı ile elde edilen kompozitlerin sertlik değerlerinin çok yakın olduğu belirlenmiştir.
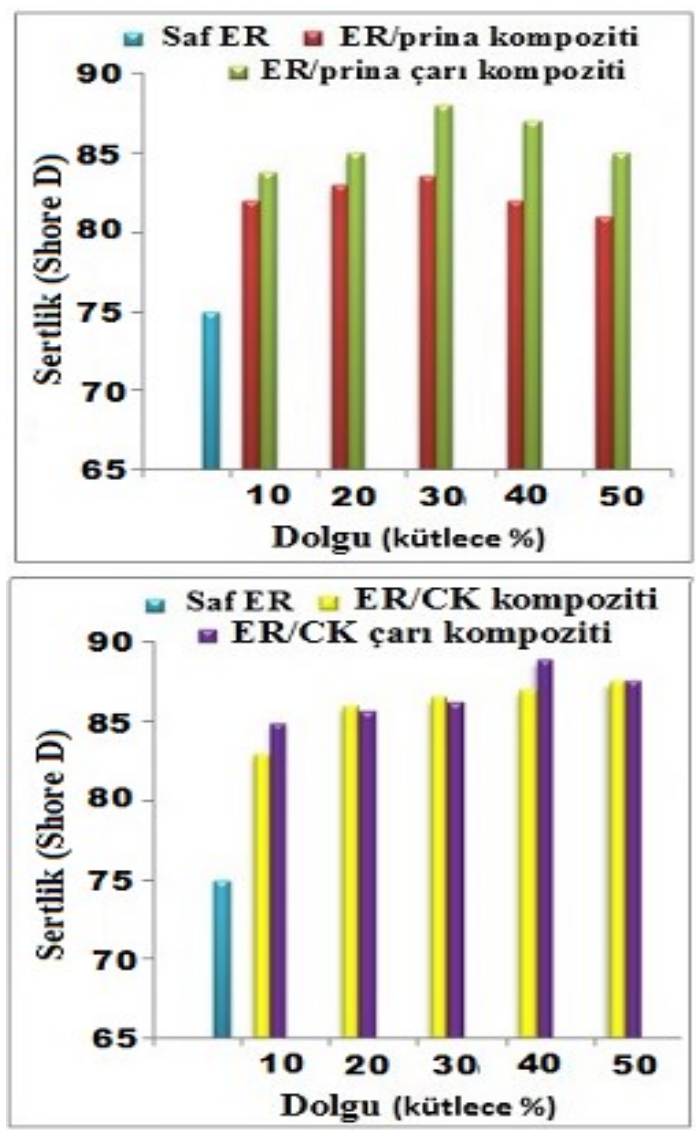

Şekil 11. a) Pirina ve pirina çarı kompozitlerinin, b) CK ve CK çarı kompozitlerinin sertlik grafikleri

\subsubsection{ER/Çar Kompozitlerinin Termal Özellikleri}

TGA analizi, çarların termal dayanımının saf atıklara göre çok daha yükssek olduğunu göstermiş̧iir (Şekil 9). Bu nedenle termal dayanım analizi için \%50'lik çar kompozitleri seçilmiş̧ir. Çizelge 7'de pirina ve $\mathrm{CK}$ atıklarının $700^{\circ} \mathrm{C}$ sicaklıkta gerçekleştirilen pirolizinden elde edilen çarlarla epoksi reçine bazlı kompozit malzemelerin \%50 çar dolgu oranı için TGA analiz sonuçları verilmiştir. 
Çizelge 7. Saf epoksi reçine ve $\% 50$ çar kompozitlerinin termal bozunma sıcaklıkları

\begin{tabular}{|c|c|c|c|c|c|c|}
\hline $\begin{array}{c}\begin{array}{c}\text { Çar } \\
\text { (küt.\%) }\end{array} \\
\end{array}$ & $\begin{array}{l}\text { BBS } \\
\left({ }^{\circ} \mathrm{C}\right)\end{array}$ & \begin{tabular}{|l|} 
İBS \\
$\left({ }^{\circ} \mathrm{C}\right)$
\end{tabular} & $\begin{array}{c}\mathbf{T}_{5} \\
\left({ }^{\circ} \mathbf{C}\right)\end{array}$ & \begin{tabular}{|l|}
$T_{10}$ \\
$\left({ }^{\circ} \mathrm{C}\right)$
\end{tabular} & \begin{tabular}{|l|}
$\mathbf{T}_{50}$ \\
$\left({ }^{\circ} \mathbf{C}\right)$
\end{tabular} & \begin{tabular}{|c|}
800 \\
${ }^{\circ} \mathrm{C}$ 'da kalıntı (\%)
\end{tabular} \\
\hline \multicolumn{7}{|c|}{ saf ER } \\
\hline- & 125 & 275 & 220 & 245 & 375 & 8 \\
\hline \multicolumn{7}{|c|}{ ER/pirina çarı kompoziti } \\
\hline 50 & 205 & 440 & 265,3 & 302,8 & 413,7 & 39.4 \\
\hline \multicolumn{7}{|c|}{ ER/CK çarı kompoziti } \\
\hline 50 & 220 & 330 & 251 & 279,7 & 448 & 43 \\
\hline
\end{tabular}

[BBS: Birinci bozunma sıcaklığı; İBS: İkinci bozunma sicaklığı: $\mathrm{T}_{5}, 10,50: \% 5, \% 10$ ve $\% 50$ bozunmanın gerçekleştiği sıcaklıklar]

Saf ER'nin ilk termal bozunma sicaklığı $125{ }^{\circ} \mathrm{C}$ 'dır. Bu aşamadaki bozunma, kürlenmiş epoksi reçinenin son hidroksil grubunun bozunması ve olefin oluşumuna bağlı olabilir. $275^{\circ} \mathrm{C}$ 'da görülen ikinci bozunma aşamasında ise bisfenol-A grubunun bozunma gösterdiği tahmin edilebilir [20]. $\mathrm{T}_{5}, \mathrm{~T}_{10}$ ve $\mathrm{T}_{50}$ sicaklıkları ne kadar yüksekse, kompozitin termal kararlığı da o kadar yüksek olmaktadır. Çizelge 7'ye göre epoksi kompozite çar ilavesi ile kompozitlerin BBS, İBS ve $\mathrm{T}_{5}, \mathrm{~T}_{10}$ ve $\mathrm{T}_{50}$ sıcaklık değerlerinin yükseldiği gözlenmiştir. \%50 bozunma için gereken ortam sıcaklığı, \%50 orana sahip pirina çarı katkılı kompozit için $413,7^{\circ} \mathrm{C}$ iken, \%50 orana sahip CK çarı kompoziti için $448{ }^{\circ} \mathrm{C}$ değerine ulaşmıştır. Çizelge 7'de verilen değerlerden CK çarı kompozitinin termal dayanıklılığının pirina çarı kompozitine göre yüksek olduğu görülmüştür.

\subsubsection{ER/Çar Kompozitlerinin Elektriksel İletkenliği}

Epoksi kompozit oluşumunda ham piroliz çarlarının kullanımı, karbon fiber kullanımı durumuna göre daha az maliyet gerektirmektedir. $\mathrm{Bu}$ amaçla tarafimızdan farklı kütle oranlarında çarlar ile oluşturulmuş epoksi kompozitlerin iletkenliği araştırılmış ve sonuçlar Çizelge 8 'de verilmiştir. Elektrik iletkenliği aralığına göre malzemeler; iletkenler $\left(10^{4}-10^{6} \mathrm{~S} / \mathrm{cm}\right)$, yarı iletkenler $\left(10^{2}-10^{-9} \mathrm{~S} / \mathrm{cm}\right)$ ve yalitkanlara $\left(10^{-22}-10^{-14} \mathrm{~S} / \mathrm{cm}\right)$ ayrılmışlardır.
Çizelge 8. Kompozitlerinin elektriksel iletkenlik değerleri

\begin{tabular}{|c|c|c|}
\hline \multirow{2}{*}{$\begin{array}{c}\text { Çar } \\
\text { (kütlece \%) }\end{array}$} & \multicolumn{2}{|c|}{ Elektriksel iletkenlik (S/cm) } \\
\cline { 2 - 3 } & $\begin{array}{c}\text { Pirina çarı } \\
\text { kompozitleri }\end{array}$ & $\begin{array}{c}\text { CK çarı } \\
\text { kompozitleri }\end{array}$ \\
\hline 10 & $5,12 \times 10^{-8}$ & $1,56 \times 10^{-7}$ \\
\hline 20 & $5,24 \times 10^{-7}$ & $3,24 \times 10^{-6}$ \\
\hline 30 & $3,20 \times 10^{-7}$ & $7,36 \times 10^{-5}$ \\
\hline 40 & $8,18 \times 10^{-5}$ & $5,35 \times 10^{-4}$ \\
\hline 50 & $2,13 \times 10^{-5}$ & $4,55 \times 10^{-3}$ \\
\hline
\end{tabular}

Çizelge 8'den elektrik iletkenliğinin kompozitlerdeki çar oranının artmasıyla birlikte arttığı açıkça görülmektedir. İyi bir yalıtkan olan epoksinin elektrik iletkenliği $10^{-14} \mathrm{~S} / \mathrm{cm}$ 'dir, fakat \%10-50 çar dolgusu içeren kompozitler yarı iletken seviyededir. Farklı içeriklerdeki kompozitlerin iletkenliği $10^{-8}-10^{-3} \mathrm{~S} / \mathrm{cm}$ aralığında değer almaktadır. Elde edilen çar kompozitlerinin elektriksel iletkenliği epoksiye göre çok daha yüksek olduğu için, kompozitlerin elektrik iletkenliğinin tam olarak çar dolgu maddesine bağlı olduğu varsayılabilir. En yüksek elektriksel iletkenlik sonuçları CK çar kompozitleri ile elde edilmiştir. $\mathrm{Bu}$, çarların kimyasal yapısı ile açıklanabilir; aromatik kondensleşme derecesinin çarların en önemli karakteristiği olduğu iyi bilinmektedir. Öncelikle tüm çarlar yoğunlaşmış aromatik halka kümeleri oluşturmakta ve artan 1sıl işlem sıcaklığı ile moleküler ölçekli değişiklikler elektriksel iletkenlikte değişikliklere neden olmaktadır [21]. CK çarı diğerlerine göre daha yüksek karbon içeriğine sahiptir. Pantea ve arkadaşları [22] çarın poliaromatik özelliğinin onun elektrik iletkenliğini arttırdığını tespit etmiştir. Tüm çarların FTIR spektrumlarından (Şekil 6 ve Şekil 7) da onların aromatik özelliğe sahip oldukları açıkça görülmektedir.

\subsubsection{Kompozitlerin Biyobozunurluk Özellikleri}

Biyobuzunma, organik yapıların mineralizasyonunu mikroorganizmalar ile tanımlayan bir prosestir. Bu mikroorganizmalar biyomalzemeyi karbondioksite, metana, suya ve biyokütleye dönüştürmektediler. Kompozitlerin biyobozunma özelliğini incelemek 
Doğal Atık Malzemeler ve Biyoçarları ile Biyobozunur Özellikte Yeni Epoksi-Bazlı Kompozitlerin Hazırlanması ve Karakterizasyonu

için ağırlıkça \%50 oranında iki farklı doğal takviye malzemesi (pirina ve CK) ile oluşturulan kompozitler kullanılmıştır. Kompozitlerin toprağa

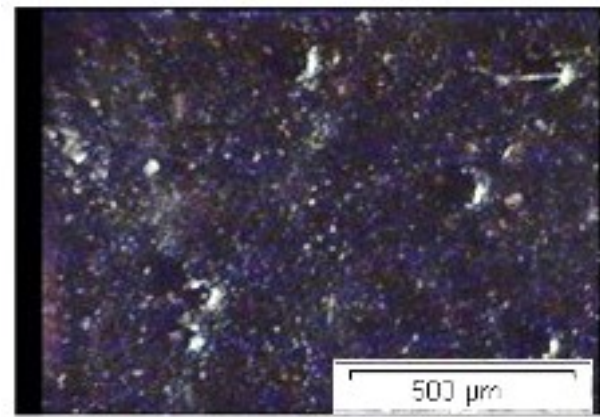

ER/pirina kompoziti (ilk hali)

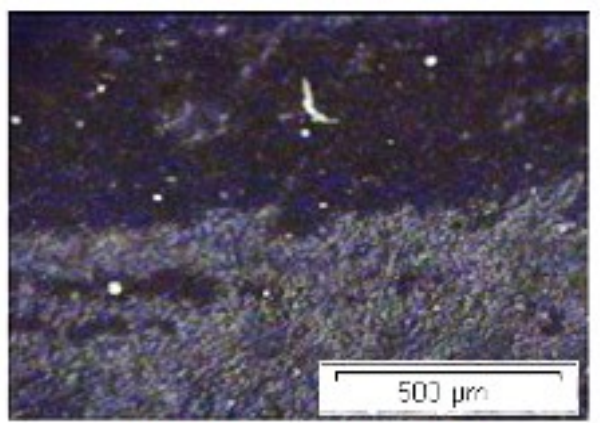

ER/CK kompoziti (ilk hali) gömülmeden önceki ve 9 ay sonraki polarize mikroskop görüntüleri Şekil 12'de verilmiştir.

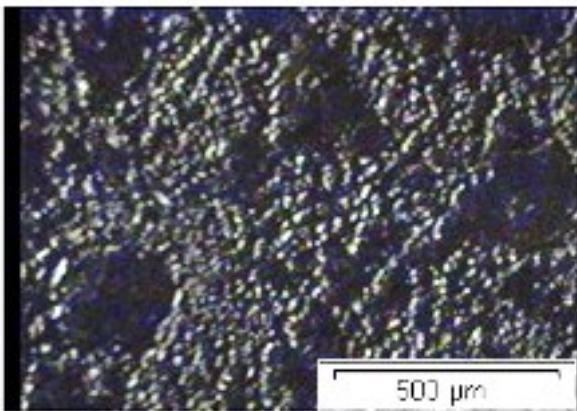

ER/pirina kompoziti ( 9 ay son ra)

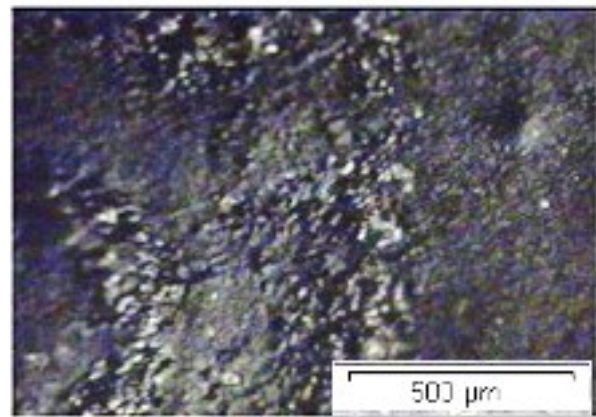

ER/CK kompoziti

(9 ay sonra)

Şekil 12. Kompozitlerin toprağa gömülmeden önceki ve sonraki polarize mikroskop görüntüleri (mag: 2,52x)

Kompozitlerin biyobozunurluk testi sonrasındaki görüntüleri incelendiğinde (Şekil 12), pirina ve CK kompozitlerinin yüzeylerinde pürüzlülük (yıpranma) olduğu ve yüzeylerinde çukurlar oluştuğu gözlemlenmiştir.

\section{SONUÇLAR}

Doğal atıklarla (pirina ve ceviz kabuğu) onların piroliz katı ürünü çarlar, epoksi kompozitlerin hazırlanmasinda uygun biyo-dolgu maddeleri olarak kullanılmıştır. Kompozitlerin farklı özelliklerine dolgu maddesi oranının ve dolgu türünün etkisi incelenmiştir. Saf epoksi reçinenin çekme uzaması tüm takviye türü içeriklerinde azalmıştır. Çarların dolgu olarak kullanıldığı kompozitlerin çekme mukavemeti değerlerinin, saf pirina ve CK dolgulu olanlara göre daha yüksek olduğu belirlenmiştir. Tüm kompozitlerin sertlik değerleri 80 Shore D'nin üzerinde tespit edilmiştir. CK çarı kompozitinin termal dayanıklılığının pirina çarı kompozitine göre yüksek olduğu görülmüştür. Tüm çar kompozitlerinin yarı iletken oldukları belirlenmiştir. Biyobozunurluk testi sonucu her iki doğal atıkla hazırlanan malzemelerin yüzeylerinde pürüzlülük (yıpranma) ve yapıda çukurlar oluşması bu kompozitlerin petrol kökenli malzemelere alternatif olduğunu kanıtlamıştır. 


\section{TEŞEKKÜR}

Bu çalışma Selçuk Üniversitesi Bilimsel Araştırma Projesi Koordinatörlüğü tarafindan kabul edilen 15401164 nolu proje kapsamında desteklenmiştir.

\section{KAYNAKLAR}

1. Mustata, F., Tudorachi, N., Rosu, D., 2012. Thermal Behavior of Some Organic/Inorganic Composites Based on Epoxy Resin and Calcium Carbonate Obtained From Conch Shell of Rapana Thomasiana, Composite Part B-Engineering, 43, 10-702.

2. Azeez, A.A., Rhee, K.Y., Park, S.J., Hui, D., 2013. Epoxy Clay NanocompositesProcessing, Properties and Applications: A Review, Composites Part B: Engineering,, 45, (1), 308-320.

3. May, C.A., 1973. Epoxy Resins: Chemistry and Technology, Marcel Dekker, 50-70, New York.

4. Ellis, B., 1993. Chemistry and Technology of Epoxy Resins, Blackie Academic and Professional, 200-300, UK.

5. Behera, A.K., Avancha, S., Basak, R.K., Sen, R., Adhikari, B., 2012. Fabrication and Characterizations of Biodegradable Jute Reinforced Soy Based Green Composites, Carbohydrate Polymers, 88(1), 329-335.

6. Fraga, F., Vazquez, I., Rodriguez-Nunez, E., Martinez-Ageitos, J.M., Miragaya, J., 2009. Influence of the Filler $\mathrm{CaCO}_{3}$ on The Cure Kinetic of the Epoxy Network Diglycidyl Ether of Bisphenol A (BADGE $\mathrm{N}=0$ ) with İsophorone Diamine, Journal of Applied Polymer Science, 114, 3338-42.

7. Özdemir, E., 2014. Organik Olarak Modifiye Edilmiş Montmorillonitlerin Poli(laktik asit)'in Termal Bozunum Davranışı ve Mekanik Özellikleri Üzerindeki Etkisi, Orta Doğu Teknik Üniversitesi Fen Bilimleri Enstitüsü, Ankara.

8. Nakamura, Y., Yamaguchi, M., Okubo, M., Matsumoto, T., 1992. Effects of Particle-Size on Mechanical and Impact Properties of Epoxy-Resin Filled with Spherical Silica,
Journal of Applied Polymer Science, 45, 1281-1290.

9. Gross, R.A., Kalra, B., 2002. Biodegradable Polymers for the Environment, Green Chemistry, 297, 803-806.

10. Maiti, S., Banerjee, P., Purakayastha, S., Ghosh, B., 2008. Silicon-Doped Carbon Semiconductor from Rice Husk Char, Materials Chemistry and Physics, 109(1), 169-173.

11. Robertson, J., 1991. Hard Amorphous (Diamond-Like) Carbons, Progress in Solid State Chemistry, 21(4), 199-333.

12. Fusco, G., Tagliaferro, A., Milne, W.I., Robertson, J., 1997. Paramagnetic Centres in Tetrahedral Amorphous Carbon, Diamond and Related Materials, 6(5), 783-786.

13. Özaytekin, İ., Kar, Y., 2012. Synthesis and Properties of Composites of Oligoazomethine with Char, Journal of Applied Polymer Science, 123(2), 815-823.

14. Paglicawan, M.A., Kim, J.K., Bang, D.S., 2010. Dispersion of Multiwalled Carbon Nanotubes in Thermoplastic Elastomer Gels: Morphological, Rheological, and Electrical Properties, Polymer Composites, 31(2), 210-217.

15. Athanasopoulos, N., Baltopoulos, A., Matzakou, M., Vavouliotis, A., Kostopoulos, V., 2012. Electrical Conductivity of Polyurethane/MWCNT Nanocomposite Foams, Polymer Composites, 33(8), 1302-1312.

16. Ahmetli, G., Kocaman, S., Ozaytekin, I., Bozkurt, P., 2013. Epoxy Composites Based on Inexpensive Char Filler Obtained from Plastic Waste and Natural Resources, Polymer Composites, 34(4), 500-509.

17. Aslanov, T., 2017. Pirina ve Plastik Atıklarının ko-Pirolizinden Elde Edilen Çarın Kullanımı ile Biyokompozitler Üretimi ve Karakterizasyonu, Yüksek Lisans Tezi, Selçuk Üniversitesi Fen Bilimleri Enstitüsü, Konya.

18. Yu, J.., Lucas, J.A., Wall, T.F., 2007. Formation of the Structure of Chars During Devolatilization of Pulverized Coal and its Thermoproperties: A Review, Progress in Energy and Combustion Science, 33(2), 135-170. 
Doğal Atık Malzemeler ve Biyoçarları ile Biyobozunur Özellikte Yeni Epoksi-Bazlı Kompozitlerin Hazırlanması ve Karakterizasyonu

19. Tan, C., Yaxin, Z., Hongtao, W., Wenjing, L., Zeyu, Z., Yuancheng, Z., Lulu, R., 2014. Influence of Pyrolysis Temperature on Characteristics and Heavy Metal Adsorptive Performance of Biochar Derived from Municipal Sewage Sludge, Bioresource Technology, 164, 47-54.

20. Bozkurt, P., 2014. Epoksi Reçine/Çar Kompozitlerinin Hazırlanması ve Karakterizasyonu, Yüksek Lisans Tezi, Selçuk Üniversitesi Fen Bilimleri Enstitüsü, Konya.

21. Mcbeath, A.V., Smernik, R.J., 2009. Variation in the Degree of Aromatic Condensation of Chars, Organic Geochemistry, 40(12), 1161-1168.

22. Pantea, D., Darmstadt, H., Kaliaguine, S., Roy, C., 2003. Heat-Treatment of Carbon Blacks Obtained by Pyrolysis of Used Tires. Effect on the Surface Chemistry, Porosity and Electrical Conductivity, Journal of Analytical and Applied Pyrolysis, 67(1), 55-76. 